ZAGONEL, J.; REGHIN, M.Y.; DALLA PRIA, M.; KUNZ, R.P. Avaliação de inseticidas no controle de Myzus persicae (Sulz.) (Homoptera: Aphididae) na cultura da alface. Horticultura Brasileira, Brasília, v. 20, n. 3, p. 514-515, setembro 2002.

\title{
Avaliação de inseticidas no controle de Myzus persicae (sulz.) (homoptera: aphididae) na cultura da alface
}

\author{
Jeferson Zagonel'; Marie Y. Reghin ${ }^{1}$; Maristella Dalla Pria ${ }^{1}$; Reni Pedro Kunz ${ }^{2}$ \\ ${ }^{1}$ UEPG, Praça Santos Andrade, 1, 84.010-790, Ponta Grossa - PR; ${ }^{2}$ Syngenta Proteção de Cultivos Ltda, Av, Nações Unidas, 18001, \\ 04.795-900, São Paulo - SP; E-mail: jefersonzagonel@uol.com.br
}

\section{RESUMO}

Foi avaliada a eficiência de inseticidas no controle de Myzus persicae (Sulz.) na cultura da alface, cv. Verônica, em experimento conduzido na UEPG, em 1999. Usou-se delineamento experimental de blocos ao acaso com seis tratamentos e quatro repetições. Os tratamentos constaram de thiamethoxam nas doses de 50; 75 e $100 \mathrm{~g}$ i.a./ha; imidacloprid na dose de $140 \mathrm{~g}$ i.a./ha; pymetrozine na dose de $150 \mathrm{~g}$ i.a./ha e testemunha sem pulverização. Os tratamentos foram aplicados nas mudas em bandejas, um dia antes do transplantio. Avaliou-se a fitotoxicidade, o número de pulgões por planta, a porcentagem de plantas com pulgões e a eficiência dos inseticidas. $\mathrm{O}$ thiamethoxam nas doses de 50; 75 e $100 \mathrm{~g}$ i.a./ha foi eficiente no controle de $M$. persicae durante todo o ciclo, mostrando eficiência igual ou superior a $98,6 \%$, similar ao imidacloprid. O pymetrozine apresentou eficiência no controle de M. persicae até 21 dias após o transplante das mudas. Os inseticidas não causaram efeitos fitotóxicos nas plantas de alface; além disso, houve produção de plantas com maior massa fresca em relação à testemunha.

Palavras-chave: Lactuca sativa L., pulgões, controle químico.

\begin{abstract}
Evaluation of insecticides to control Myzus persicae (Sulz) (Homoptera: Aphididae) on lettuce crop

A field trial was carried out at Universidade Estadual de Ponta Grossa, State of Paraná, Brazil, in 1999, to evaluate the efficiency of insecticides in controlling Myzus persicae (Sulz) on lettuce cv. Veronica. The experimental design was of completely randomized blocks with six treatments and four replications. The treatments consisted of thiamethoxam (50; 75 and $100 \mathrm{~g}$ i.a/ha) imidacloprid (140 g i.a/ha); pymetrozine ( $150 \mathrm{~g}$ i.a/ha) and control. The treatments were applied to seedlings grown in polyestyrene trays one day before the transplanting. The fitotoxicity, the number of aphids/plant, the percentage of plants with aphids and the efficiency of the insecticides were evaluated. Thiamethoxan at doses of 50; 75 and $100 \mathrm{~g}$ i.a/ha was efficient to control $M$. persicae from transplanting till 43 days after showing equal or higher efficiency than $98.6 \%$, similar to imidacloprid. The pymetrozine was efficient to control M. persicae until 21 days after transplanting. Effects of fitotoxicity on lettuce plants were not observed. Higher fresh weight was observed in treated plants in comparison to the one of the control.
\end{abstract}

Keywords: Lactuca sativa L., aphids, chemical control.

(Recebido para publicação em 24 de agosto de 2001 e aceito em 27 de março de 2002)

\begin{abstract}
$\mathrm{A}$ alface está entre as dez hortaliças mais apreciadas para consumo in natura no Brasil (Porto, 1996), sendo a folhosa de maior importância econômica. Durante o desenvolvimento vegetativo, as folhas podem ser prejudicadas por ocorrência de pragas, e dentre estas, os pulgões constituem uma das mais importantes por interferirem negativamente na produção e na qualidade do produto. Entre as espécies de pulgões que atacam as hortaliças, o Myzus persicae (Sulzer, 1776) (Homoptera: Aphididae) destaca-se como uma das principais pragas. Tem cerca de $2 \mathrm{~mm}$ de comprimento, a forma áptera apresenta coloração verde clara e a forma alada coloração verde com cabeça, antenas e tórax pretos. Em clima seco e quente, as novas fêmeas tornam-se adultas e passam a reproduzir-se em 2 a 3 dias. Atacam as folhas sugando a seiva. Em conseqüência, induzem o
\end{abstract}

encarquilhamento e o enrolamento das folhas. Além disso, são vetores de vírus (Zucchi, 1993), podendo transmitir na alface a virose principal da cultura, o mosaico. Um dos meios para o controle de pulgões é o químico, com uso de inseticidas. No entanto, o seu emprego deve ser criterioso pois trata-se de uma planta com ciclo curto e consumida in natura. Entre os inseticidas utilizados no controle de pulgões encontra-se o imidacloprid, do grupo das nitroguanidinas (Andrei, 1999). Outro produto, ainda em fase de registro para a alface é o thiamethoxam, do grupo dos neonicotinóides, que apresenta como características o efeito residual longo e baixa toxicidade ao homem e ao ambiente. O presente trabalho teve como objetivo avaliar a eficiência e a seletividade de diferentes inseticidas no controle de Myzus persicae (Sulzer, 1776) na cultura da alface.

\section{MATERIAL E MÉTODOS}

O experimento foi realizado na Universidade Estadual de Ponta Grossa, no delineamento experimental de blocos ao acaso, com seis tratamentos [thiamethoxam (Actara $250 \mathrm{WG}$ ) nas doses de 50; 75 e 100 g i.a./ha; imidacloprid (Confidor 700 GRDA) na dose de 140 g i.a./ha; pymetrozine (Chess) na dose de $150 \mathrm{~g}$ i.a./ha e testemunha] e quatro repetições. As parcelas apresentaram área total de $6,0 \mathrm{~m}^{2}(5,0$ x 1,2 m) e área útil de $4,8 \mathrm{~m}^{2}(4,0 \times 1,2$ $\mathrm{m})$. A semeadura foi realizada em 22/ 10/99 em bandejas de poliestireno expandido com 288 células. Os inseticidas foram diluídos em $400 \mathrm{ml}$ de água e aplicados (drench) sobre as mudas nas bandejas com um frasco contendo seis furos na tampa. O tratamento ocorreu no dia 24/11/99, às $17: 30$ horas, com 
Tabela 1. Número de pulgões/planta, porcentagem de controle, número de plantas com pulgão e massa frescas das plantas de alface em função de diferentes inseticidas. Ponta Grossa, UEPG, 1999.

\begin{tabular}{|c|c|c|c|c|c|c|c|c|}
\hline \multirow{2}{*}{ Nome comum } & \multirow{2}{*}{$\begin{array}{c}\text { Dose } \\
\text { (ge.a/ha) }\end{array}$} & \multicolumn{3}{|c|}{ Número de pulgões/planta } & \multirow{2}{*}{$\begin{array}{c}\text { Controle }{ }^{1} \\
\text { E\% }\end{array}$} & \multirow{2}{*}{$\begin{array}{c}\text { Plantas cl } \\
\text { pulgão } \\
(\%)\end{array}$} & \multicolumn{2}{|c|}{$\begin{array}{c}\text { Peso fresco } \\
\text { (g/planta) }\end{array}$} \\
\hline & & $21 \mathrm{DAT}^{2}$ & 34 DAT & 43 DAT & & & 34 DAT & 43 DAT \\
\hline Thiamethoxam & 50 & 0 & $0 \mathrm{a}$ & $0,3 a$ & 99,0 & $0 \mathrm{a}$ & $80,2 a$ & $190,5 a$ \\
\hline Thiamethoxam & 75 & 0 & $0 \mathrm{a}$ & $0,4 a$ & 98,6 & $0 \mathrm{a}$ & $90,4 a$ & $210,4 a$ \\
\hline Thiamethoxam & 100 & 0 & $0 \mathrm{a}$ & $0,1 a$ & 99,7 & $3,1 a$ & $79,8 a$ & $195,7 a$ \\
\hline Imidacloprid & 140 & 0 & $0 \mathrm{a}$ & $0,1 \mathrm{a}$ & 99,7 & $3,3 a$ & $79,2 a$ & $200,3 a$ \\
\hline Pymetrozine & 150 & 0 & $5,5 \mathrm{~b}$ & $12,0 \mathrm{~b}$ & 59,2 & $40,6 \mathrm{~b}$ & $69,9 a$ & $170,4 a b$ \\
\hline Testemunha & - & 0,3 & $4,3 \mathrm{~b}$ & $30,6 \quad c$ & - & $62,5 \mathrm{~b}$ & $40,5 \mathrm{~b}$ & $134,1 \mathrm{~b}$ \\
\hline$\overline{\text { C.V. }}$ & - & - & 48,7 & 28,1 & - & 57,7 & 16,4 & 10,9 \\
\hline
\end{tabular}

Nas colunas, médias seguidas de mesma letra, não diferem significativamente pelo teste de Tukey ( $<<5 \%$ );

${ }^{1}$ Porcentagem de eficiência (Abbott) em relação ao número de pulgões/planta aos 43 dias após o transplante;

${ }^{2}$ Dias após o transplante;

temperatura no local de $28^{\circ} \mathrm{C}$. Após a aplicação da calda, usou-se mais $400 \mathrm{ml}$ de água para lavagem das folhas e para drenar o excesso de produto para o substrato da bandeja a fim de atingir as raízes. No dia do tratamento, as mudas de alface, cv. Verônica, apresentavam de 2 a 3 folhas e foram transplantadas no dia seguinte à aplicação (em 25/11/99), no espaçamento $0,30 \times 0,30 \mathrm{~m}$. A adubação consistiu da aplicação de $500 \mathrm{~kg} /$ ha de esterco de gado curtido no preparo dos canteiros e $45 \mathrm{~kg} / \mathrm{ha}$ de nitrogênio na forma de uréia aos 25 dias após o transplante. A área do experimento foi irrigada por aspersão. Foram avaliados em 10 plantas por parcela, a fitotoxicidade, o peso fresco da planta, o número de folhas por planta, o número de pulgões por planta e a porcentagem de plantas com pulgão. Os dados obtidos foram submetidos à análise da variância pelo teste $\mathrm{F}$ e, quando significativas as diferenças entre as médias, estas foram comparadas pelo teste de Tukey no nível de 5\% de probabilidade. Para análise dos resultados do número de pulgões/planta e da porcentagem de plantas com pulgão, os dados foram transformados para raiz de $(x+0,5)$. A porcentagem de eficiência foi calculada através da fórmula de Abbott (Nakano et al., 1981).

\section{RESULTADOS E DISCUSSÃO}

A incidência de Myzus persicae (pulgões) foi mais acentuada a partir de 21 dias após o transplante (DAT) das mu- das, data na qual foi realizada a primeira avaliação. Nesta data, observou-se incidência da praga apenas na testemunha (Tabela 1). Aos 34 e 43 DAT, nos tratamentos com thiamethoxam em todas as doses e para imidacloprid, o número de pulgões por planta foi significativamente inferior ao verificado para o pymetrozine e para a testemunha. A eficiência (Abbott) destes tratamentos foi igual ou superior a $98,6 \%$ aos 43 DAT, demonstrando que os produtos mantiveram sua eficiência desde o transplante até próximo à colheita. O pymetrozine foi eficiente até 21 DAT, e a partir daí sua eficiência diminuiu gradativamente até 43 DAT. Para a porcentagem de plantas com pulgão, observou-se que em plantas tratadas com thiamethoxam e com imidacloprid ocorreram valores baixos, confirmando novamente a eficiência destes produtos no controle dos pulgões. Deve ser destacado que, além do aspecto fisiológico (sugamento da seiva), os pulgões podem danificar as folhas de várias maneiras (encarquilhamento e lesões); deste modo, os tratamentos que mantêm as folhas livres da presença de pulgões são os mais desejados, uma vez que a alface é consumida in natura e o aspecto visual é de suma importância. Tanto o thiamethoxam como o imidacloprid mostraram vantagem tanto no sentido de garantir um menor número de plantas com pulgões como na manutenção de um baixo número destes nas plantas atacadas, fatores altamente benéficos para a qualidade do produto final. Outra vantagem destes produtos é a manutenção do controle até 43 DAT, o que garante o desenvolvimento da cultura sem a presença de pulgões desde o transplante até a colheita, com apenas uma aplicação. Os inseticidas utilizados não promoveram efeitos fitotóxicos nas plantas de alface, uma vez que características como número de plantas vivas, desenvolvimento das plantas, coloração e aspecto das folhas foram avaliados e não mostraram diferenças entre os tratamentos. Nas parcelas com tratamento inseticida houve desenvolvimento de plantas de maior peso fresco em relação à testemunha (Tabela 1).

\section{LITERATURA CITADA}

ANDREI, E. Compêndio de Defensivos Agrícolas. São Paulo: Organização Andrei Editora Ltda, 1999. $672 \mathrm{p}$.

BELFOR, C.C., MOURA FÉ, E.A., SANTOS,

H.L. Determinação do ponto de colheita em alface em condições de cultivo protegido: hidroponia. In: CONGRESSO BRASILEIRO DE OLERICULTURA, 38. Petrolina, 1998. Resumos... SOB: Petrolina, 1998. p. 30.

CORREIO AGRÍCOLA. Principais pragas da olericultura. Correio agrícola, jan/jul de 2000, p. 12-6. FILGUEIRA, F.A.R. Manual de olericultura: cultivo e comercialização de hortaliças. Vol. II, 2 ed. São Paulo: Ceres, 1982.

PORTO, V.C.N. Efeitos de fontes de matéria orgânica na produção de alface. Mossoró: ESAM, 1996. 35 p. (monografia).

TAVARES, H.L., JUNQUEIRA, A.M.L., PEIXOTO, J.R. Produção hidropônica de alface cv. Verônica em diferentes substratos. In: CONGRESSO BRASILEIRO DE OLERICULTURA, 38. Petrolina, 1998. Resumos... SOB: Petrolina, 1998. p. 345.

NAKANO, O., SILVEIRA NETO, S., ZUCCHI, R.A. Entomologia econômica. Piracicaba: Livroceres, 1981. 314 p.

ZUCCHI, R.A. Guia de identificação de pragas agricolas. In: ZUCCHI, R.A., SILVEIRA NETO, S., NAKANO, O. Piracicaba: FEALQ, 1993. 139 p. 